Article

\title{
Shades of Green: Life Cycle Assessment of a Urethane Methacrylate/Unsaturated Polyester Resin System for Composite Materials
}

\author{
Jonathon M. Chard ${ }^{1,2}$, Lauren Basson ${ }^{1}$, Gavin Creech ${ }^{2}$, David A. Jesson ${ }^{1, * \mathbb{D}}$ and Paul A. Smith ${ }^{1}$ \\ 1 Department of Mechanical Engineering Sciences, Faculty of Engineering and Physical Sciences (A1), \\ University of Surrey, Guildford, GU2 7XH Surrey, UK; jonmchard@googlemail.com (J.M.C.); \\ lauren@green-cape.co.za (L.B.); p.smith@surrey.ac.uk (P.A.S.) \\ 2 Scott Bader Company Ltd., Wollaston, NN29 7RL Northamptonshire, UK; Gavin.Creech@kilwaughter.com \\ * Correspondence: d.jesson@surrey.ac.uk; Tel.: +44-(0)1483-686299; Fax: +44-(0)1483-686291
}

Received: 21 December 2018; Accepted: 12 February 2019; Published: 15 February 2019

\begin{abstract}
Bio-derived fibres and resins are of increasing interest as alternatives to petrochemicals in the production of so-called environmentally friendly composite materials. However, whilst the majority of systems consider complete replacement, another route is to look at the constituents that are required to give certain properties, including the content of diluents; a third is to identify 'hot spots' in manufacturing. This paper considers these three possibilities in the context of the production of a resin system, and presents results from a life cycle assessment. The aim of this study was to make qualitative assertions based on quantitative estimates. The current work provides a practical assessment of the contribution of the manufacturing process of a multi-part resin formulation to a range of environmental impacts. As a part of this, a multi-stage methodology, the first of its kind, which is more relevant for the batch processes used to manufacture many structural thermosetting polymer systems, was developed. This was applied to a range of resins, some of which include bio-mass derived precursors. For the boundary conditions used, the indications are that the impacts due to taking the constituents and processing them to produce the resin system are insignificant compared with those due to producing the feedstocks in the first place. Surprisingly, whether the feedstocks were from fossil resources or were bioderived was of little significance. As a consequence of the analysis, it has been demonstrated that whilst a manufacturer can make significant savings through careful management of plant and the supporting energy mix, significant improvements to the environmental impacts of resin systems can be made through the choice of particular monomers.
\end{abstract}

Keywords: composites; diluent; formulation; life cycle assessment; resins; styrene

\section{Introduction}

\subsection{Sustainability in the Context of Composite Materials}

The terms 'green composite' and 'ecocomposite' are becoming more prevalent in the composites literature; however, they are being used to define a number of different things simultaneously [1-3], describing either a material that is derived from biomass or a material which has superior environmental properties, or both. The term bioplastic is also used, but this is usually limited to thermoplastics, typically derived from long chains processed from e.g., starches, sugars and the like [4]. As the level of understanding with regard to this class of composites matures, it is becoming more obvious that a) the terminology that is applied must become more stringently defined, b) usage must become more precise and c) that bio-derived composites are not necessarily 'green' $[5,6]$. 
In terms of materials, it must be remembered that sustainability is a property of the system and not of the material [7]. This is particularly relevant in the context of composite materials where the system not only consists of a plethora of raw materials, but the materials produced can be handled in a number of different ways (wet lay-up, pre-preg, etc.) and used in myriad applications in a number of sectors including aerospace, automotive, construction and marine, seeing a range of service conditions before end-of-life disposal by a number of different routes. Disposal in particular represents a significant issue as the intimate combination of two or more separate materials makes higher level actions within the waste hierarchy [8] difficult if not impossible.

\subsection{Green Composites}

As the price of raw materials for resins is heavily dependent on petrochemical price fluctuations, there has been a greater focus on deriving these resins from bio-based sources e.g., [9]. There is also an interest in deriving fibres from biomass e.g., [10], although the term 'green composite' is most often associated with natural fibres, typically plant and animal fibres [11]. A range of factors must be considered when working with such fibres, see e.g., [12-14], but in general 'as produced' fibres tend to be short and lack the uniformity one finds in manufactured fibres. Hence, waste biomass can be locally sourced and used to give a serviceable material; however, it is not usually suitable for advanced engineering applications, although such materials are perfectly adequate in other milieus.

While these fibres do have interesting properties that merit further attention, and while there is the potential to process them to a greater or lesser extent in order to produce more uniform and longer fibres (e.g., [15]), there is perhaps greater potential in the investigation of resin systems and the processes by which they can be made more sustainable. For those interested in developing such methodologies, "Polymers, The Environment and Sustainable Development" [16] is recommended.

Recent work has considered these issues [17-19]; in particular, 'sustainability' was measured in terms of the proportion of the resin system that was replaced by a bio-derived oil, displacing fossil-based petrochemicals [19].

The focus of the present paper will be to provide a more robust assessment of the 'green credentials' of this class of materials. To this end, life cycle assessment (LCA, sometimes referred to as life cycle analysis) has been undertaken in order to assess existing options and to provide a baseline against which alternatives can be compared.

\subsection{Life Cycle Assessment of Composites}

Life cycle assessment (LCA) is a generic term for a range of 'inventory' techniques, which began to appear in multiple places independently during the late 1960s and early 1970s: see e.g., [20]. Fundamentally, the purpose of such inventory techniques is to gather all available information on the production, use and disposal of a given item, and hence, to determine the impact of the item on the environment.

Ideally, an LCA will be cradle-to-cradle, i.e. one which consolidates the impacts arising from every stage, starting with raw material extraction/sourcing, production, distribution, useful lifetime, and end of life, continuing right through to the processing of the discarded item and its subsequent re-processing in order to produce raw materials for another product [21]. Composites are complex materials with multiple potential inputs, multiple processing routes, multiple end-uses and (theoretically, at least) multiple reprocessing routes, and as such the boundary conditions applied to an LCA are likely to be more stringent than in some other contexts.

LCA has become the central concept for both environmental management within industry and governmental environmental policy making [22]. The international standards that cover LCAs are BS EN ISO 14040 [23] and BS EN ISO 14044 [24]. The framework of the LCA has been written such that it can be applied to any goods or service. The LCA can be subdivided into foreground and background systems. The foreground consists of processes that can be affected as a result of decisions based upon the study. The background consists of all of the other processes within the study. Owing to 
the complexity of many goods and services, in order to encompass the breadth of the system, a study will need to make a number of simplifications:

i. system boundaries are applied to a study to limit the amount of data collected;

ii. generic data for supporting processes are used; and

iii. representation of the process based upon average performance.

On this basis, two kinds of LCA can be defined: attributional and consequential. The purpose of the former is to be able to provide an assessment of a specific product that can be compared on a like for like basis with similar products. Such an analysis may, for example, inform an eco-label that allows a consumer to compare refrigerators. By contrast, a consequential LCA can afford to be less precise in certain areas, particularly with respect to background data, but also, potentially, with respect to foreground systems that are not of interest to the study. Here then, one might be interested in comparing the production of a specific kind of refrigerator and the changes that might be made from using a different refrigerant. In this case, the transport of the refrigerator to the shop from the factory will be the same (unless the mass of the refrigerators is very different) and could potentially be ignored if accurate data were not available. The inputs and outputs of the system are generalised (grouped) into various impacts of interest. It should be noted that these will be impact potentials, not the real impacts that will be experienced [22]. This is done so that it is possible to identify the impacts of greatest concern (hotspot analysis). A hotspot will indicate where the greatest focus should be in improving the sustainability of a product or service.

Some products are easier to assess than others. For example, products that are feedstocks for multiple users are much more complex to provide an inventory for, and of course polymers and polymer matrix composites fall into this category. The important thing to carry forward is that it is not always possible to provide an assessment that is perfectly accurate, usually due to the lack of good quality (or any) data when preparing the inventory. This can be perceived as a major barrier to carrying out an assessment, but even generalised assessments can be valuable in highlighting issues within the production, use, and disposal of an item. Another perceived issue is the complexity of processing and manufacturing; however, streamlining methodologies have been found to be very successful in highlighting issues in production, which would not be captured if LCA was reserved as a corporate strategic tool e.g., [7].

LCAs of various composites have been carried out including natural fibre systems [25] comparisons of natural fibre and glass fibre systems [5] and composite parts for specific applications [26,27]. It has also been noted that LCA is frequently carried out after the part has been produced, when in fact, using materials selection techniques and a fundamental knowledge of composite materials, it should be possible to carry out the LCA before the part is produced [28]: this represents a significant challenge to the assertion that LCA should be kept apart from the design process [29].

LCA of polymer resins typically used in composite systems has been carried out previously, e.g., [30-32]. Such studies follow typical LCA processes and limit the scope of the study quite severely, making many assumptions to simplify the case as much as possible, e.g.:

- in some cases, only energy inputs and materials that directly report the resin system were included, whereas in some, other aspects (cleaning, transport, etc.) were included;

- batch processes were typically modelled in an aggregated manner, i.e., as if all inputs and output occurred at once, or rather summing over all inputs or outputs; and

- all the studies showed that the raw materials had a greater environmental impact compared to on site production, despite differences in system boundaries, or different results which could be expected due to the differences in system boundaries.

A more in-depth study has been carried out, which goes so far as to consider specific health issues that might arise through the lifetime of a particular polymer [33]: despite failing to distinguish between thermosets and thermoplastics and making the assumption that bioderived feedstocks will form a 
separate class of materials rather than being used to replace petrochemical feedstocks for existing resin formulations, this work does provide an exemplar when comparing a number of different polymers.

\subsection{Current Work}

Thermosetting polymer resins provide the majority of matrices for fibre reinforced polymer composites. A number of different resins are available, but most represent large families of different systems that can be tailored for specific applications, such that a number of precursors are used. Typically, these are derived from petrochemical sources, although it is possible to source some precursors from refined bio-mass.

The aim of the current work was to provide a practical assessment of the contribution of the manufacturing process of a multi-part resin formulation to a range of environmental impacts. As a part of this, a multi-stage methodology, the first of its kind, which is more relevant for the batch processes used to manufacture many structural thermosetting polymer systems, was developed, and this has been applied to a range of resins, some of which include bio-mass derived precursors. In the following sections, details are given of the resin systems examined and the precise methodology employed, including boundary conditions for the LCA. The results are presented and discussed, enabling a range of conclusions to be made.

\section{Materials and Methodology}

\subsection{Materials}

The current research is based on a commercially available resin system: this system, together with development variations, the production process and the results have been anonymised. The two main types of thermosetting resin systems that are manufactured at Scott Bader's site at Wollaston are unsaturated polyesters (UPs) and urethane methacrylates (UMas); sometimes these are blended. In the previous work, a urethane methacrylate/unsaturated polyester resin system was used in the preparation of natural fibre and cellulosic fibre reinforced polymer composites [17-19], and hence, this resin was used here as the baseline system. This system was produced by combining a base resin (henceforth referred to as ' $R$ '), with additions of two other resins (A1 and A2) to form the final resin system. In the current study, identical monomers derived from petrochemical and biomass sources were compared, together with different diluents/diluent content.

The raw materials for these resin systems arrive on site either by lorry (24+ ton) or tanker (21+ ton). The liquid based raw materials are stored in tanks and can then be pumped into a reaction vessel (the reactor). The solid raw materials are transported around the site by forklift truck.

The resin system is manufactured in a six ton capacity reactor: the capacity of the reactor was chosen as the functional unit for the assessment. As noted above, LCA of the manufacture of polymer resin systems is usually aggregated when in reality it is usually a multi-stage process. These stages can vary in duration (e.g., several minutes to hours) and operating temperature (hence the reactor and its contents require heating or cooling (as appropriate) and different raw materials are added at each stage. The reactors at Scott Bader are steam heated. This steam is produced on site by gas powered boilers. The reactor is cooled using cold water in a closed system (a cooling tower is located on site). The stirrer within the reactor is constantly on during the manufacture of the resin to ensure sufficient mixing. In addition, nitrogen gas is pumped into the reactor at a flow rate of $201 . \mathrm{min}^{-1}$ in order to purge the reactor of volatiles. This nitrogen is supplied from a liquid source. The stirrers within the reactors are electrically powered with a variable load motor. The electricity is supplied from the National Grid.

Once manufacture is completed, the resin is stored in containers. The reactor is then cleaned with a cleaning agent. This cleaning agent is reused four times before it is reprocessed into fresh cleaning agent (recycled). The resin systems are commonly stored in one ton intermediate bulk containers (IBCs). When a resin system leaves for a customer, it can be transported in sizes ranging from a $25 \mathrm{~kg}$ steel keg to a tanker. 
The following stages have been derived from the batch process sheet (i.e. the formal manufacturing instructions) for this resin system:

1. Initial base polymers, catalysts and inhibitors are put into the reactor. This first stage contributes approximately $25 \%$ of the final mass of the batch. The raw materials within the reactor are heated to $80{ }^{\circ} \mathrm{C}$.

2. Once the temperature of the reactor has stabilised at $80{ }^{\circ} \mathrm{C}$, the reactive component raw material is drip-fed into the reactor. This component equates to $15 \%$ of the final mass. It takes roughly two hours for this stage to complete. Owing to the exothermic reaction, no heating or cooling was required to hold the temperature at $80^{\circ} \mathrm{C}$. The piping system is flushed with a small amount of diluent.

3. The reactor is then maintained at a temperature of $80{ }^{\circ} \mathrm{C}$ for the next two to three hours with steam heating.

4. The reactor is cooled to $40{ }^{\circ} \mathrm{C}$. The bulk of the cross-linking agent is added ( $30 \%$ of the final mass). Within this stage there is the addition of approximately $10 \%$ of another urethane methacrylate base resin and approximately $15 \%$ of an unsaturated polyester base resin.

In order to visualise the different stages of manufacture for the resin system, an initial flow diagram was created, Figure 1. The next section takes this overview of the resin production and considers this in the context of carrying out a life cycle analysis. The methodology used here, with boundary conditions, is described.

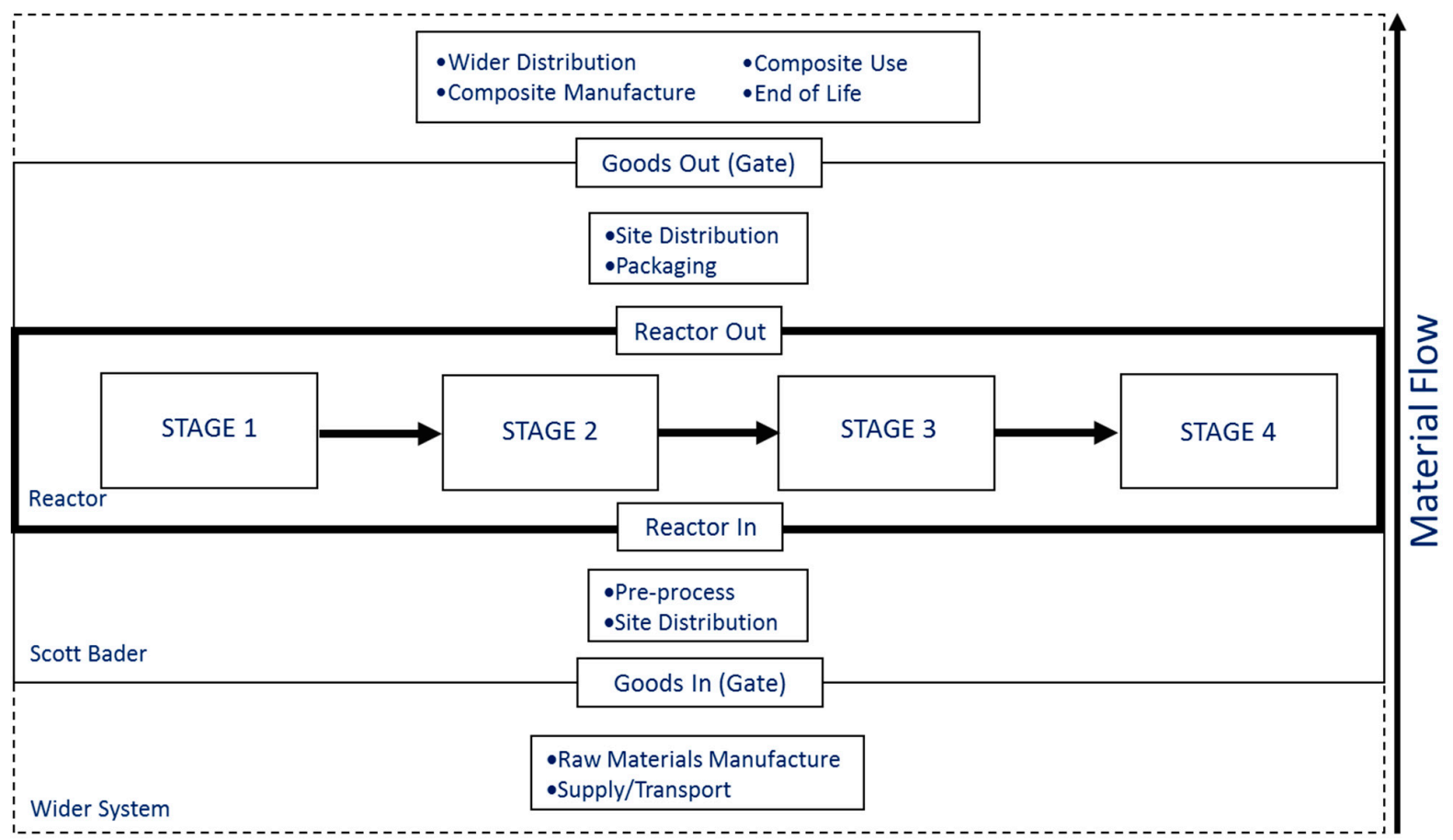

Figure 1. Flow diagram of the manufacture of the resin system from arrival of precursors to 'goods out' (gate).

\subsection{Life Cycle Assessment Methodology}

The resin system at the centre of the current study is used in a wide range of applications, and therefore, in the current context, a cradle-to-cradle assessment was not possible and a cradle-to-grave LCA would not be appropriate. Instead, the current work focuses on the production of the resin in a cradle-to-gate analysis: here, 'gate' is taken to mean the output from the reactor, rather than the factory gate, as the subsequent effects are (a) negligible and (b) the same for all systems produced. 
Initially, the material flow for the LCA was broken down into five main areas, which cover cradle-to-gate (Figure 1). These areas are the manufacture of the raw materials and transport to site ("Wider System"), pre-processing and site distribution ("Scott Bader" from Goods In to Reactor In), the production process ("Reactor" from Reactor In to Reactor Out), post-processing (from Reactor Out to Goods Out) and Lifetime (Goods Out to End of Life). For the current cradle-to-gate analysis, the latter two stages were not included.

Where LCAs were carried out for polymers, the production stage is usually treated as one process and various assumptions were made to account for the different steps in the manufacturing process. Here, the Reactor stage was broken down into four sub-stages in order to more accurately assess the energy used during batch production. The sensitivity of the system to changes in raw materials was investigated.

As the formulation of the resin systems utilises specialist monomers, the data for some of these chemicals were not available. In a number of instances $(25 \%)$, it was possible to find data for another isomer of that chemical and it was thus assumed that the supply chain and production conditions for two isomers would be quite similar. Within the model, data were not available for approximately $20 \%$ of the final mass. Whilst this is not an ideal situation for an LCA, it is by no means unusual and is discussed in depth in the Handbook on Life Cycle Assessment [34]. It is suggested that typically one can cut off a flow for which there is insufficient data if it contributes less than $1 \%$ of the total flow. This can be measured in economic or mass terms. Whilst no guidance is provided on what the total amount of omitted mass can be, it is acknowledged that a total of $20 \%$ of the final mass is quite a considerable proportion to omit from consideration. However, these components are a) minor constituents (catalysts and inhibitors in the resin, for example, amounted to less than $0.1 \%$ ) and $b$ ) are generally found in both the commercial and developmental resins, and therefore, can be treated as having a comparable effect on both systems.

An LCA can consider a number of environmental impact categories. In the current context, Non-Renewable/Abiotic Resource Depletion or Land Use have not been considered; instead, the LCA focuses on:

- $\quad$ Acidification Potential (AP) ( $\mathrm{kg} \mathrm{SO}_{2}$ equivalent)

- $\quad$ Eutrophication Potential (EP) (kg phosphate equivalent)

- Freshwater Aquatic Ecotoxicity Potential (FAEP) (kg dichlorobenzene, DCB, equivalent)

- Global Warming Potential (GWP) (100 years) (kg. $\mathrm{CO}_{2}$ equivalent)

- Human Toxicity Potential (HTP) (kg DCB equivalent)

- Ozone Layer Depletion Potential (OLDP) (kg R11 equivalent)

- Photochemical Oxidant Creation Potential (POCP) (kg Ethene equivalent)

- Terrestrial Ecotoxicity Potential (TEP) (kg DCB equivalent)

The life cycle inventory analysis was completed using a software package (GaBi v.4.4). GaBi is product sustainability software developed by PE International. The software provides for data collection and management, modelling, results and interpretation analysis, and contains databases of cradle-to-gate inventories for a large number of intermediate chemicals and final products as well as energy sources (fuels, electricity, steam etc.).

As a consequence, this model used a number of new processes (excluding the repeats of the four reactor stages in the manufacture of different resins) including:

- Nitrogen Evaporation: This process assumed that $1 \mathrm{~kg}$ of liquid nitrogen input equalled $1 \mathrm{~kg}$ of nitrogen output. There are no other inputs or outputs. The nitrogen is used in the reactor is fed continuously throughout the entire manufacturing process at a constant rate.

- Reactor Stage 1: This process adds the first set of materials (monomers, diluents, catalysts, inhibitors and nitrogen gas) and energy during the first stage of manufacture and the outputs are an intermediate resin (\#1) and nitrogen gas (which is released to the atmosphere). 
- Reactor Stage 2: This process adds the new materials (monomers, diluents, nitrogen gas etc.), energy and the intermediate resin (\#1) and then outputs another intermediate resin (\#2) and nitrogen gas (which is released to the atmosphere).

- Reactor Stage 3: This process adds the new materials, energy and the intermediate resin $(\# 2)$ and then outputs another intermediate resin (\#3) and nitrogen gas (which is released to the atmosphere).

- Reactor Stage 4: This final reactor stage adds the new materials, energy, intermediate resin (\#3), other resins and outputs the urethane methacrylate/unsaturated polyester resin and nitrogen gas (which is released to the atmosphere).

- Materials Collation: To assist in data management and subsequent analysis, the material inputs associated with each of the resins' (UP, UMa and blend) manufacture were grouped together.

The LCA focused only on the inputs and outputs directly associated with the manufacturing of the resin system, i.e., wastage, power and heating for factory (not linked to reactor) and on-site distribution was excluded. The reactor where the resin is manufactured was considered the foreground process (bold line in Figure 1) and study was to cover 'cradle' to 'gate'. The 'gate' of this study was set to the Reactor Out boundary (Figure 1), i.e., post-manufacture activities, such as reactor cleaning and packaging, were not considered.

As the aim of this study was to make qualitative assertions based on quantitative estimates, the results were presented as relative contributions. The main comparison of interest was the relative contribution of Scott Bader's processing (energy) input and the embodied impact of the raw materials. The data were also normalised against total European data (CML2001 EU 25+3) to understand the environmental impacts that have the greatest relative contribution.

For foreground processes, the manufacture process used quantities and timings based on the batch sheet for that particular resin. The motor rating on the reactor is $15 \mathrm{~kW}$. To calculate the heating requirements of the reactor, the individual heat capacities of the raw materials were used. The background processes included the production of these raw materials (Ecoinvent and PlasticsEurope databases-European averages where available) and an electricity mix based upon the average UK power mix. Owing to the lack of availability of exact data, it has been assumed that:

- $100 \%$ power load on stirrer for first three minutes of manufacture to approximate the energy required to get the reactants up to speed;

- $20 \%$ power load on stirrer to sustain rotation speed;

- $89 \%$ boiler efficiency from steam heating (data available closest to actual);

- Heat loss from reactor was calculated to be $5 \mathrm{~kW}\left(80{ }^{\circ} \mathrm{C}\right.$, cylindrical tank of exact dimensions, medium insulation on bottom and side) [35];

- Monomer ambient temperature was $21^{\circ} \mathrm{C}$ (room temperature);

- No heating or cooling required during Stage 2 (common operating condition);

- No energy required to convert the nitrogen from a liquid state to a gas state (energy sourced from the atmosphere);

- No volatiles were released during resin manufacture;

- No piping losses for steam heating;

- No energy required for reactor vessel to heat up;

- Unsaturated polyester manufactured modelled using a basic single stage process.

Within the boundary conditions of the system, a number of exclusions have been necessary due to a lack of appropriate data for the assessment. Some of these exclusions, such as the contribution from catalysts and inhibitors, fell within the accepted cutoffs for LCA, i.e., the total mass was less than $0.01 \%$ of the batch. Others, such as local and off-site transportation, packaging of the product, power for pumping of raw material into reactor (assumed to be low), wastage (filtering waste and remnants with reactor) and cleaning, were independent of a specific resin system. As such, whilst these would 
be required for an attributional assessment, in the context of a consequential model, these exclusions can be made.

\section{Results and Discussion}

\subsection{Overview}

The LCA model showed that of the eight environmental impacts considered, four were significant and four were not. A breakdown of the contribution from the materials as supplied and the on-site process is presented in Figure 2 and from this it can be seen that the on-site processes add comparatively little to the environmental impact of the raw materials. Further, in three out of four cases, the main resin system gives the greatest environmental impact rather than the additions. These data, for all eight environmental impact categories, were then normalised against total European data (CML2001 EU 25+3), and this normalisation is presented in Figure 3. Following a review of the raw materials, a number were noted to be giving disproportional impacts. Data from the Ecoinvent database, together with some potential alternatives is summarised in Table 1. Outputs from the model are discussed in more detail in the following sections.
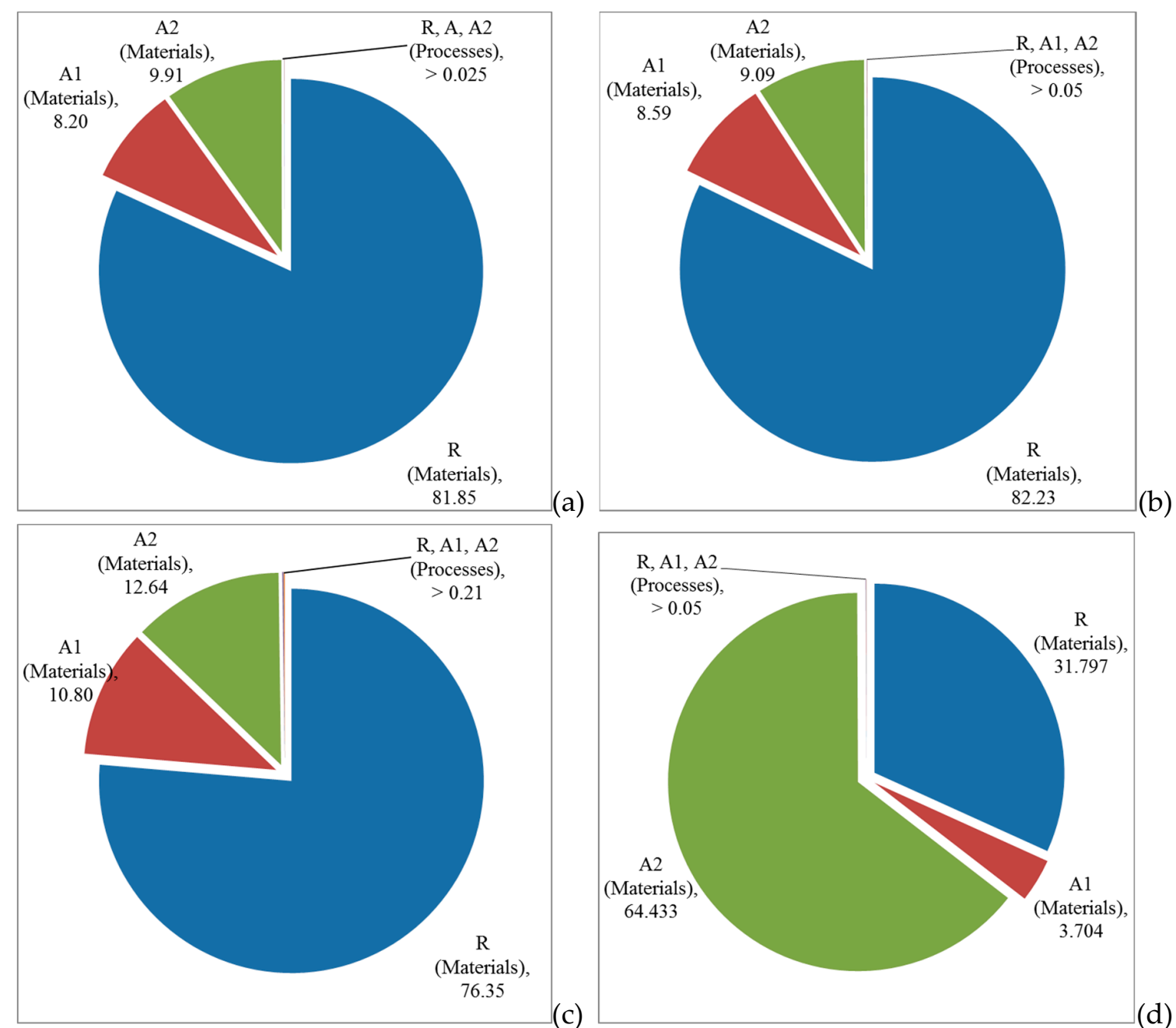

Figure 2. Breakdown of contribution to environmental impact from materials and processes involved in the production of the resin system for (a) photochemical oxidant creation potential, (b) acidification potential, (c) global warming potential (100 years) and (d) human toxicity potential. The numbers represent percentage contribution; here, the processes have been summarised into one group. 


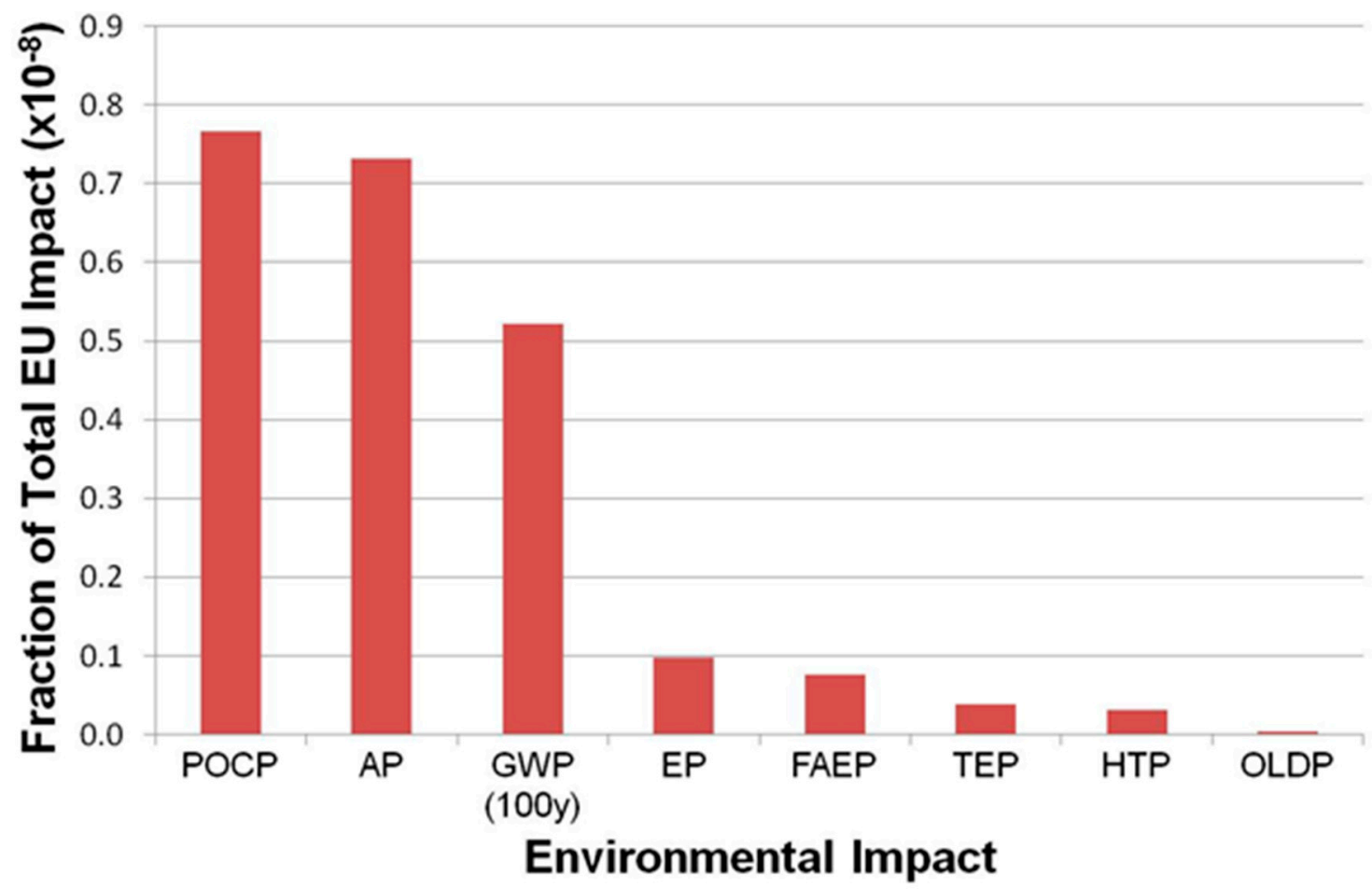

Figure 3. Environmental impacts for the production of a 6 ton batch of the resin system. These data are normalised against data for total European impacts (CML2001 EU 25+3). AP, Acidification Potential; EP, Eutrophication Potential; FAEP, Freshwater Aquatic Ecotoxicity Potential; GWP, Global Warming Potential; HTP, Human Toxicity Potential; OLDP, Ozone Layer Depletion; POCP, Potential Photochemical Oxidant Creation Potential; TEP, Terrestrial Ecotoxicity Potential.

Table 1. Environmental impacts for a selection of monomers from the Eco-invent life cycle assessment (LCA) database.

\begin{tabular}{ccccc}
\hline Monomer (1 kg) & $\begin{array}{c}\text { Global Warming } \\
\text { Potential (kg CO } \\
\text { Equivalent) per kg } \\
\text { of Monomer }\end{array}$ & $\begin{array}{c}\text { Acidification } \\
\text { Potential (kg SO } \\
\text { Equivalent) per kg } \\
\text { of Monomer }\end{array}$ & $\begin{array}{c}\text { Human Toxicity } \\
\text { Potential (kg } \\
\text { Dichclorobenzene } \\
\text { Equivalent) per kg } \\
\text { of Monomer }\end{array}$ & $\begin{array}{c}\text { Photochem. Ozone } \\
\text { Creation Potential } \\
\text { (kg Ethene } \\
\text { Equivalent) per kg of } \\
\text { Monomer }\end{array}$ \\
\hline Adipic Acid & $\mathbf{2 5 . 5 0}$ & 0.023 & 11.02 & 0.0041 \\
\hline Terephthalic Acid & 1.85 & 0.006 & 0.67 & 0.0011 \\
\hline Acrylic Acid & 2.88 & 0.005 & 0.27 & 0.0010 \\
\hline Diethylene Glycol & 1.11 & 0.004 & 0.43 & 0.0008 \\
\hline Ethylene Glycol & 1.62 & 0.005 & 0.64 & 0.0011 \\
\hline Propylene Glycol & 4.24 & 0.017 & $\mathbf{1 3 . 5 4}$ & 0.0031 \\
\hline Styrene & 3.23 & 0.010 & 0.35 & 0.0018 \\
\hline $\begin{array}{c}\text { Methyl } \\
\text { Methacrylate }\end{array}$ & 6.67 & $\mathbf{0 . 0 3 4}$ & 0.31 & $\mathbf{0 . 0 0 6 2}$ \\
\hline
\end{tabular}

Note: the highest environmental impact within each category has been emboldened.

In order to understand the effect that adjusting boundary conditions and exclusions had on a model, it was necessary to conduct a sensitivity analysis. The three areas where sensitivity analysis was conducted were the potential underestimation of heating requirements, off-site transportation and slight changes to the resin formulation. The latter is significant as commercial resin systems are frequently modified at the request of the customer in order to meet a specific criteria, whilst maintaining the overall performance of the base resin system. 


\subsection{Potential Underestimation of Energy Input for Heating}

Owing to the limited availability of data, data for an $89 \%$ efficiency steam boiler provided in the Eco-invent database was used. However, the boilers at Scott Bader are over 25 years old (non-condensing) and have an estimated efficiency of $60 \%$. In addition, there are heat losses due to piping as well as the efficiency of thermal transfer between the steam and the reactor. Potentially, therefore, there is some uncertainty over the required amount of natural gas, which could lead to underestimation of the GWP impact category. To investigate this, the model was adjusted to use five times more energy from steam. This was deliberately an extreme adjustment; the total contribution to GWP from Scott Bader's processing remained less than $1 \%$ of the total impact, increasing from $0.23 \%$ to $0.84 \%$.

This adjustment has led to the relative GWP from electricity within the 'processing' to decrease from $20 \%$ to $5 \%$. This result illustrates that in the case where on-site heating is of the order suggested here, Scott Bader's contribution to the resin's GWP potential is mainly through heating, but that electricity use would still be a significant contributor to the carbon footprint directly under Scott Bader's control (the so-called Scope 2 emissions when doing a carbon footprint), and thus, merit consideration when attempting to find opportunities for improvement in environmental performance. This also emphasises the importance of obtaining accurate information about the exact steam (and hence gas) usage.

\subsection{Off-site Transportation}

As Scott Bader has a worldwide manufacture and distribution network, the different manufacturing sites source raw materials from and distribute products to their regional area. In order to estimate the environmental impact for the transportation of the raw materials, a model was developed, which assumed that:

- these products will travel 1500 miles (equivalent distance of Wollaston, England to most edges of Europe);

- materials are transported on 32 ton trucks (24.7 ton cargo capacity) with Euro 4 emission rating;

- $40 \%$ of travel is on motorways, $40 \%$ is on out of town roads and $20 \%$ is in urban areas;

- $\quad 85 w t . \%$ cargo utilisation (accounting for empty journeys).

The results for the transportation step show that the GWP per kilogram of cargo is equivalent to $0.125 \mathrm{~kg}$ of $\mathrm{CO}_{2}$. As the GWP for one kilogram of the resin system was calculated to be equivalent to $5.7 \mathrm{~kg}$ of $\mathrm{CO}_{2}$, if transportation was included, it would represent around $2 \%$ of the total GWP of that product. In addition, transportation represented less than $1 \%$ in most of the other environmental impact categories

\subsection{Adjustments to the Formulation}

As the polymer backbone within unsaturated polyester resin systems is manufactured from a blend of saturated and unsaturated acids and alcohols, there are many permutations possible from the variety of monomers and their concentrations within a polymer system. As it is common practice to adjust the monomer concentrations within the formulation to form a new system, this alteration could have an effect on the environmental impacts.

Previously, it has been shown that the majority of the human toxicity environmental impact of the resin system was attributed to a monomer that was less than $2.5 \%$ of the formulation. Thus, if the concentration of that monomer in the formulation was increased then the human toxicity potential could become an impact of concern.

To further assist in understanding the potential issue of adjustments to a formulation, Table 1 shows some of the environmental impact categories for a selection of monomers (mass of $1 \mathrm{~kg}$ ) from the Ecoinvent database (European averages). The data within this table shows that some monomers can have environmental impacts that are an order of magnitude (or more) greater than other monomers. 
In a few instances, the monomers have generally high or low impacts across the presented categories. For example, adipic acid has shown relatively high environmental impacts, whereas diethylene glycol has relatively low environmental impacts. In other instances, the monomers have only a few categories with a high environmental impact. Methyl methacrylate has a very high acidification potential and photochemical oxidant creation potential, whereas propylene glycol has a high human toxicity potential. Therefore, adjustments to a monomer concentration within a formulation of an unsaturated polyester system should only be made after careful consideration of all the environmental impacts.

\subsection{Disproportionate Impacts}

Once the materials segments were broken down to the relative contribution of each of the resin components, it was found that the diluents contributed:

- $81 \%$ of the POCP impact.

- $73.1 \%$ of the AP impact.

- $72 \%$ of the GWP impact.

Clearly, therefore, diluents represent an area of interest for those looking to reduce material-related impacts. Whilst the role of the diluent has historically been crucial (particularly with respect to UP resin systems) in taking a material from an interesting but uneconomic material to a commercial success with widespread applications, in order to maintain this usage it is necessary to identify alternative diluents (or alternatives to diluents) with reduced impact upon the environment.

Furthermore, when the impact of the materials and processing were split, it was observed that one part of the blended system, representing around $20 \%$ of the resin system's mass, was responsible for $64 \%$ of the human toxicity potential. Further analysis showed that of this part, one monomer was the main contributor to the impact, $(52.9 \%$ of the HTP), despite contributing less than $2.5 \%$ of the resin system's mass. Therefore, this too indicates a particular area for scrutiny.

The data summarised in Table 2 suggest that the model used is providing numbers that are in the right ball park for resin systems. It was expected that the Energy Input and GWP of the resin system would be close to the results for the unsaturated polyester and epoxy resin systems, because they are both manufactured from petrochemical based feedstocks. Without over-interpreting the findings, especially when it is not possible to compare the system boundaries and assumptions for the LCAs of the three resins, it is worth noting that a possible explanation as to why the resin had a lower Energy Input and GWP is that the raw materials are different to the raw materials used in the unsaturated polyester and epoxy resins. Additionally, there may be the chance that the $20 \%$ of mass of material omitted may be responsible for this difference.

Table 2. Energy input and GWP for the resin system compared with an unsaturated polyester and epoxy resin systems.

\begin{tabular}{ccc}
\hline Resin Type & Energy Input (MJ kg $\mathbf{~ o f ~ R e s i n ) ~}^{-\mathbf{1}}$ GWP (kg CO $\mathbf{~ k g}^{\mathbf{- 1}}$ of Resin) \\
\hline Resin system & 117 & 5.7 \\
Unsaturated Polyester & 128 & 7.6 \\
Epoxy & 139 & 6.7 \\
\hline
\end{tabular}

\section{Implications}

\subsection{The Environmental Impact of Resin Production}

When the results for the environmental impact categories were broken down into the materials and process groupings it is of note that the on-site contribution to the environmental impact for the resin system was commonly less than $0.2 \%$ of the product in each of the impact categories. Even if it is 
assumed that the energy for heating was underestimated by a factor of five, the on-site contribution to the environmental impacts was still less than $1 \%$.

This analysis does not mean that resin manufacturers have no control over reducing environmental impacts. The results of the LCA suggest that there are two groups of people who have the potential to significantly reduce the environmental impact of resin systems: the polymer chemists and the purchasers of raw materials.

For example, the formulation (the monomers that make the polymer, and including the diluents that aid processability) of the resin system, can be revised with a focus on options with lower environmental impacts when developing new products. At the same time, the suppliers of the raw materials can be selected based upon the environmental impact of their product (e.g., there is usually more than one manufacturing method for a particular monomer and different manufacturers may have access to different energy sources some of which may be less carbon intensive). Even if the raw material is sourced further afield, the extra transportation environmental impact could be lower than the improved environmental impact of that particular raw material.

Interestingly, it should be noted that for the options available within the current study (i.e., oils derived from petrochemical or vegetable sources), it appears that the environmental impacts are relatively insensitive to production route from which it may be inferred that the contributions from fertilisers and harvesting are comparable to extraction from the ground. However, there is much potential for examining the choice of monomers and assessing their contribution to mechanical properties against their environmental impacts, as there can be as much as an order of magnitude difference in, e.g., GWP.

As it is common practice to adjust the monomer concentrations within the formulation to form a new system, this alteration could have an effect for the environmental impacts. For example, the current analysis has shown that the majority of the human toxicity environmental impact of the resin system was attributed to a monomer that was less than $2.5 \%$ of the formulation. Thus, if the concentration of that monomer in the formulation was increased, then the human toxicity potential could become an impact of concern.

\subsection{Strategy Informed by LCA}

Through conducting the LCA, the results also have an effect on existing polymer development strategies. Two particular strategies that have been affected are 'styrene reduction' and 'styrene replacement'.

In order for standard unsaturated polyester resins to cross-link between the polymer chains, styrene is used. As styrene is of low viscosity, it also acts to reduce the viscosity of the resin system. The common proportion of styrene within Scott Bader's resin systems is around $40 \%$. During the manufacture of composite materials it is possible for styrene evaporation to occur from the unsaturated polyester (open mould-e.g., hand lamination and spray application). This evaporation of styrene is hazardous to human health, and EU directives are pushing for threshold limit values of $50 \mathrm{ppm}$ (for average exposure over an eight hour period), with an aspiration that this should be reduced below $20 \mathrm{ppm}$ in the future: this will be extremely challenging in some industries. As a result, there has been a focus on reducing the styrene content within unsaturated polyester resin systems, with a target reduction being of $50 \%$ (i.e.to $20 w t . \%$ of the final resin system). It is, of course, worth noting that other manufacturing routes, including liquid composite molding (e.g., resin transfer molding, RTM; resin infusion under flexible tooling, RIFT) and in-mold gel-coating processes can potentially achieve significantly lowered VOC (volatile organic compound) emissions. However, such techniques are not suitable for all manufactured parts.

Previously, the data for styrene in Table 1 have shown that it has over double the global warming potential, acidification potential and photochemical ozone creation potential of many of the acids and glycols. This means that styrene reduced resin systems could have as much as a $20 \%$ reduced environmental impact, depending on the other monomers within the system. 
As a result of conducting this LCA study, there is further emphasis on this project of reducing styrene content as in addition to reducing the health impacts during use, reduction in styrene content can also improve the environmental impact of an unsaturated polyester resin system in terms of other environmental impact categories.

Following on the same lines as styrene reduction, new resins systems are being developed that use methyl methacrylate (MMA) instead of styrene in order to achieve the reduction in styrene vapours during composite manufacture. However, when the data for the environmental impacts of MMA are compared with styrene, it can be seen that MMA has a greater environmental impact (Table 1). MMA has over twice as large a global warming potential and over three times greater acidification potential and photochemical ozone creation potential compared with styrene. Hence, the results from this LCA study have called into question the current strategy of styrene replacement with MMA as this would increase the environmental impact of these new resin systems compared with the standard resin systems.

\section{Concluding Remarks}

In order to understand the environmental impacts of the thermosetting resin systems manufactured by Scott Bader Company Ltd., an environmental life cycle assessment was conducted. This assessment focused on the manufacture of a single urethane methacrylate/unsaturated polyester resin system. This assessment has considered the use of bio-derived substitutes for feedstocks currently derived from fossil sources and a hot-spot analysis of the production process in general. Furthermore, it is the first analysis of its kind to provide a breakdown of the reaction steps, rather than simply aggregating the whole process.

The results from a model, created using $\mathrm{GaBi}$, showed that the three environmental impact categories of particular significance were photochemical ozone creation potential, acidification potential and global warming potential. The results also illustrated that the manufacturing stage contributed less than $0.2 \%$ of the impact for all impact categories, i.e., that the extraction of the raw materials was the most significant contributor in a "cradle to factory gate" study.

As a consequence of the analysis, it has been demonstrated that whilst a manufacturer can make significant savings through careful management of plants and the supporting energy mix, significant improvements to the environmental impacts of resin systems can be made through the choice of particular monomers.

Some monomers form a disproportionately large portion of the environmental impact of the final product. In particular, diluents seem to be the most significant monomers to focus on in any environmental assessment. Furthermore, through sensitivity analysis for a selection of monomers, the data showed that the current strategy of 'styrene reduction' could have a positive environmental impact, whereas 'styrene replacement' could have a negative environmental impact depending on the replacement monomer used.

Overall, this study has demonstrated the value of doing an environmental life cycle assessment to support product development, procurement strategies and on-site operations.

Author Contributions: Formal analysis, J.M.C. and L.B.; Investigation, J.M.C.; Methodology, L.B.; Supervision, G.C., D.J. and P.A.S.; Writing - original draft, D.J.; Writing - review \& editing, G.C., D.J. and P.A.S.

Funding: The authors would like to acknowledge the sponsorship of this project by the EPSRC, via the MiNMaT IDC (Grant \# EP/G037388/1) hosted by the University of Surrey.

Conflicts of Interest: The authors declare no conflict of interest.

\section{References}

1. Baillie, C. Eco-composites. Compos. Sci. Technol. 2003, 63, 1223-1224. [CrossRef] 
2. Dicker, M.P.M.; Duckworth, P.F.; Baker, A.B.; Francois, G.; Hazzard, M.K.; Weaver, P.M. Green composites: A review of material attributes and complementary applications. Compos. Part A Appl. Sci. Manuf. 2014, 56, 280-289. [CrossRef]

3. La Mantia, F.P.; Morreale, M. Green composites: A brief review. Compos. Part A Appl. Sci. Manuf. 2011, 42, 579-588. [CrossRef]

4. Reddy, M.M.; Vivekanandhan, S.; Misra, M.; Bhatia, S.K.; Mohanty, A.K. Biobased plastics and bionanocomposites: Current status and future opportunities. Prog. Polym. Sci. 2013, 38, 1653-1689. [CrossRef]

5. Joshi, S.V.; Drzal, L.T.; Mohanty, A.K.; Arora, S. Are natural fiber composites environmentally superior to glass fiber reinforced composites? Compos. Part A Appl. Sci Manuf. 2004, 35, 371-376. [CrossRef]

6. Thomason, J.L. Why are natural fibres failing to deliver on composite performance? In Proceedings of the 17th International Conference on Composite Materials, ICCM17, Edinburgh, UK, 27-31 July 2009.

7. Weston, N.; Clift, R.; Holmes, P.; Basson, L.; White, N. Streamlined life cycle approaches for use at oil refineries and other large industrial facilities. Ind. Eng. Chem. Res. 2011, 50, 1624-1636. [CrossRef]

8. European Commission. European Commission Directive 2008/98/EC. Waste framework directive. Off. J. Eur.Union 2008, L312, 3.

9. Thakur, V.K.; Thakur, M.K.; Raghavan, P.; Kessler, M.R. Progress in green polymer composites from lignin for multifunctional applications: A Review. ACS Sustain. Chem. Eng. 2014, 2, 1072-1092. [CrossRef]

10. Lewandowska, A.E.; Soutis, C.; Savage, L.; Eichhorn, S.J. Carbon fibres with ordered graphitic-like aggregate structures from a regenerated cellulose fibre precursor. Compos. Sci. Technol. 2015, 116, 50-57. [CrossRef]

11. Pickering, K.L. (Ed.) Properties and Performance of Natural-Fibre Composites; Woodhead Publishing: Cambridge, UK, 2008.

12. Summerscales, J.; Dissanayake, N.; Virk, A.; Hall, W. A review of bast fibres and their composites. Part 2 Composites. Compos. Part A Appl. Sci. Manuf. 2010, 41, 1336-1344. [CrossRef]

13. Summerscales, J.; Dissanayake, N.; Virk, A.; Hall, W. A review of bast fibres and their composites. Part 1-Fibres as reinforcements. Compos. Part A Appl. Sci. Manuf. 2010, 41, 1329-1335. [CrossRef]

14. Summerscales, J.; Virk, A.; Hall, W. A review of bast fibres and their composites: Part 3-Modelling. Compos. Part A Appl. Sci. Manuf. 2013, 44, 132-139. [CrossRef]

15. Einsiedel, R.; Uihlein, K.; Ganster, J.; Rihm, R. Cordenka Reinforced PLA-Advanced Bio-derived Composite Material. In Proceedings of the 68th Annual Technical Conference of the Society of Plastics Engineers 2010 (ANTEC 2010), Society of the Plastics Industry, Orlando, FL, USA, 16-20 May 2010; pp. 306-311.

16. Azapagic, A.; Emsley, A.; Hamerton, I. Polymers: The Environment and Sustainable Development; John Wiley \& Sons: Chichester, UK, 2003.

17. Chard, J.M.; Creech, G.; Jesson, D.A.; Smith, P.A. Green composites: Sustainability and mechanical performance. In Proceedings of the 18th International Conference on Composite Materials ICCM, Jeju Island, Korea, 21-26 August 2011.

18. Chard, J.M.; Creech, G.; Jesson, D.A.; Smith, P.A. Coupling agent for natural fibre composites utilising thermosetting resin systems. In Proceedings of the 15th European Conference on Composite Materials ESCM, Venice, Italy, 24-28 June 2012.

19. Chard, J.M.; Creech, G.; Jesson, D.A.; Smith, P.A. Green composites: Sustainability and mechanical performance. Plast. Rubber Compos. 2013, 42, 421-426. [CrossRef]

20. Jensen, A.A.; Hoffman, L.; Møller, B.T.; Schmidt, A.; Christiansen, K.; Elkington, J.; van Dijk, F. Life Cycle Assessment: A Guide to Approaches, Experiences and Information Sources; Environmental Issues Series No. 6; European Environment Agency: Copenhagen, Denmark, 1997.

21. Braungart, M.M.; Donough, M.W. Cradle to Cradle Remaking the Way We Make Things; Vintage: New York, NY, USA, 2002.

22. Baumann, H.; Tillman, A.-H. The Hitch Hiker's Guide to LCA; Studentlitteratur: Lund, Sweden, 2004.

23. BS EN ISO 14040. Environmental Management_Life Cycle Assessment_Principles and Framework; International Organization for Standardization: Geneva, Switzerland, 2006.

24. BS EN ISO 14044. Environmental Management-Life Cycle Assessment-Requirements and Guidelines; International Organization for Standardization: Geneva, Switzerland, 2006.

25. Batouli, S.M.; Zhu, Y.; Nar, M.; D'Souza, N.A. Environmental performance of kenaf-fiber reinforced polyurethane: A life cycle assessment approach. J. Clean. Prod. 2014, 66, 164-173. [CrossRef] 
26. Song, Y.S.; Youn, J.R.; Gutowski, T.G. Life cycle energy analysis of fiber-reinforced composites. Compos. Part A Appl. Sci. Manuf. 2009, 40, 1257-1265. [CrossRef]

27. Witik, R.A.; Payet, J.; Michaud, V.; Ludwig, C.; Månson, J.A. Assessing the life cycle costs and environmental performance of lightweight materials in automobile applications. Compos. Part A Appl. Sci. Manuf. 2011, 42, 1694-1709. [CrossRef]

28. Le Duigou, A.; Baley, C. Coupled micromechanical analysis and life cycle assessment as an integrated tool for natural fibre composites development. J. Clean. Prod. 2014, 83, 61-69. [CrossRef]

29. Millet, D.; Bistagnino, L.; Lanzavecchia, C.; Camous, R.; Poldma, T. Does the potential of the use of LCA match the design team needs? J. Clean. Prod. 2007, 15, 335-346. [CrossRef]

30. Hischier, R. Polyester resin, unsaturated. In Life Cycle Inventories of Chemicals; Report No. 8.; Althaus, H.-J., Chudacoff, M., Hischier, R., Jungbluth, N., Osses, M., Primas, A., Eds.; Ecoinvent, Swiss Centre for Life Cycle Inventories: Zurich, Switzerland, 2007.

31. Wilson, J.B. Life-cycle inventory of formaldehydebased resins used in wood composites in terms of resources, emissions, energy and carbon. Wood Fiber Sci. 2010, 42, 125-143.

32. Kočí, V.; Loubal, T. LCA of liquid epoxy resin produced based on polypropylene and glycerine. Acta Environ. Univ. Comen. 2012, 20, 62-67.

33. Álvarez-Chávez, C.R.; Edwards, S.; Moure-Eraso, R.; Geiser, K. Sustainability of bio-based plastics: General comparative analysis and recommendations for improvement. J. Clean. Prod. 2012, 23, 47-56. [CrossRef]

34. Guinee, J.B. (Ed.) Handbook of Life Cycle Assessment: Operation Guide to ISO Standards; Kluwer Academic Publishers: Secaucus, NJ, USA, 2002.

35. Spiraxsarco. Tank Heating-Heat Losses and Steam Load. Online Calculator. 2012. Available online: http:/ / www.spiraxsarco.com/esc/heatloss_tankheating.aspx?shape=1 (accessed on 16 August 2012).

(C) 2019 by the authors. Licensee MDPI, Basel, Switzerland. This article is an open access article distributed under the terms and conditions of the Creative Commons Attribution (CC BY) license (http:/ / creativecommons.org/licenses/by/4.0/). 